\title{
Eye Choice for Acquisition of Targets in Alternating Strabismus
}

\author{
John R. Economides, ${ }^{1}$ Daniel L. Adams, ${ }^{1,2}$ and Jonathan C. Horton ${ }^{1}$ \\ ${ }^{1}$ Beckman Vision Center, Program in Neuroscience, University of California, San Francisco, San Francisco, California 94143, and ${ }^{2}$ Center for Mind/Brain \\ Sciences, The University of Trento, 38122 Trento, Italy
}

In strabismus, potentially either eye can inform the brain about the location of a target so that an accurate saccade can be made. Sixteen human subjects with alternating exotropia were tested dichoptically while viewing stimuli on a tangent screen. Each trial began with a fixation cross visible to only one eye. After the subject fixated the cross, a peripheral target visible to only one eye flashed briefly. The subject's task was to look at it. As a rule, the eye to which the target was presented was the eye that acquired the target. However, when stimuli were presented in the far nasal visual field, subjects occasionally performed a "crossover" saccade by placing the other eye on the target. This strategy avoided the need to make a large adducting saccade. In such cases, information about target location was obtained by one eye and used to program a saccade for the other eye, with a corresponding latency increase. In 10/16 subjects, targets were presented on some trials to both eyes. Binocular sensory maps were also compiled to delineate the portions of the visual scene perceived with each eye. These maps were compared with subjects' pattern of eye choice for target acquisition. There was a correspondence between suppression scotoma maps and the eye used to acquire peripheral targets. In other words, targets were fixated by the eye used to perceive them. These studies reveal how patients with alternating strabismus, despite eye misalignment, manage to localize and capture visual targets in their environment.

Key words: diplopia; exotropia; saccade; scan path; anomalous retinal correspondence; suppression

\section{Introduction}

In normal subjects, the visual environment is explored through constant execution of saccades (Dodge, 1919; Buswell, 1935). When an object of interest appears, its image falls on corresponding points in the peripheral retina of each eye. A conjugate saccade moves the eyes so that the target is projected onto each fovea. Target selection for saccades has been investigated intensively in normal subjects (Basso and Wurtz, 1998; Krauzlis et al., 2004; Kayser et al., 2006; Noudoost et al., 2010; Hall and Colby, 2011; Kowler, 2011; Schall et al., 2011; Tatler et al., 2011; Burr and Morrone, 2012). However, little is known about this topic in strabismic subjects. In strabismus, the situation is more complicated because the foveae are directed at two different locations.

There are many different forms of strabismus. To narrow the scope of our inquiry we have concentrated on intermittent exotropia. This condition has a distinct phenotype, which accounts for $\sim 30 \%$ of strabismus cases (Mohney, 2007). Initially, individ-

\footnotetext{
Received Aug. 7, 2014; revised Sept. 12, 2014; accepted Sept. 22, 2014.

Author contributions: J.R.E., D.L.A., and J.C.H. designed research; J.R.E., D.L.A., and J.C.H. performed research; J.R.E., D.L.A., and J.C.H. analyzed data; J.R.E., D.L.A., and J.C.H. wrote the paper.

This work was supported by grants EY10217 (J.C.H.) and EY02162 (Beckman Vision Center) from the National Eye Institute and by a Physician Scientist Award from Research to Prevent Blindness. James V. Botelho assisted with computer programming. We thank the ophthalmologists who referred subjects, especially Omondi L. Nyong'0 and Naureen Mirza-George. We are grateful to the strabismic subjects for making this study possible.

The authors declare no conflicting financial interests.

Correspondence should be addressed to Dr. Jonathan C. Horton, Beckman Vision Center, University of California, San Francisco, 10 Koret Way, San Francisco, CA 94143-0730. E-mail: hortonj@vision.ucsf.edu.

DOI:10.1523/JNEUROSCI.3278-14.2014

Copyright $\odot 2014$ the authors $\quad 0270-6474 / 14 / 3414578-11 \$ 15.00 / 0$
}

uals enjoy normal binocular development, intact stereopsis, and good acuity in both eyes (Hoyt and Pesic, 2012). However, their exophoria eventually decompensates into intermittent exotropia (Nusz et al., 2006; Romanchuk et al., 2006; Eibschitz-Tsimhoni et al., 2007; Buck et al., 2012). Subjects switch between epochs of ocular fusion and exotropia (Hatt et al., 2008). When diverged, they engage in strabismic suppression to avoid diplopia. Usually they are able to alternate fixation and retain good acuity in both eyes. In some subjects, exotropia eventually becomes constant and stereopsis can be lost (Hunter et al., 2001; Chia et al., 2007; Choi and Kim, 2013).

Recently, we mapped the visual fields in subjects with exotropia to determine how sensory information is suppressed to avoid diplopia (Economides et al., 2012). In agreement with others (Cooper and Feldman, 1979; Herzau, 1980; Joosse et al., 1999; Serrano-Pedraza et al., 2011), there was regional suppression of the peripheral temporal retina in each eye. This is accompanied by loss of metabolic activity in the temporal retina's ocular dominance columns in peripheral striate cortex (Tychsen and Burkhalter, 1997; Adams et al., 2013). In the present study, we address how subjects with exotropia guide their eyes to acquire targets in the visual scene.

It is common for a person with alternating exotropia to view a target with one eye and make an accurate saccade to fixate a new target with the other eye (van Leeuwen et al., 2001). It is unknown how this feat is accomplished. It is possible that the new target is perceived via the peripheral retina in the initially fixating eye. In that case, to program an appropriate movement for the other eye, 
the brain would have to take into account the exotropia to calculate the correct vector of the intended saccade. Alternatively, the new target might be detected via the peripheral retina in the deviated eye. The brain could then derive saccade parameters directly from information provided by the eye destined to acquire the new target. The third possibility is that either eye could supply the information required to make an appropriate saccade for a fixation swap.

To resolve this issue, we presented targets dichoptically to subjects with alternating exotropia that were visible to the fixating eye, the deviated eye, or to both eyes. We then compared the subjects' choice of eye for target acquisition with the organization of their suppression scotomas. This approach revealed the strategies used by individuals with alternating exotropia to make saccades to visual targets.

\section{Materials and Methods}

Participants. Sixteen subjects with exotropia were enrolled in this study: ages $8-49$ years, 6 male, 10 female. None contributed to our previous study of exotropia (Economides et al., 2012). Seven subjects had intermittent exotropia, with stereoacuity of 80 arc-sec or better. Nine subjects had constant exotropia and no stereopsis. Subjects were referred by ophthalmologists practicing in the San Francisco Bay Area. Adults gave informed consent; minors gave assent and a parent provided informed consent. The study was approved by the University of California San Francisco Committee on Human Research and by the Kaiser Permanente Northern California Institutional Review Board. Subjects were paid a stipend to reimburse travel expenses.

Eligibility. All subjects received an ophthalmological examination, which included assessment of the best-corrected visual acuity in each eye, refractive error, pupils, color discrimination (Ishihara plates), eye movements, ocular alignment, and stereopsis (Randot circles and stereo butterfly). Slit lamp and fundus examinations were also performed. Inclusion criteria were as follows: (1) 20/20 Snellen acuity in each eye measured with best refractive correction, (2) exotropia since early childhood, (3) no eye disease except strabismus, (4) ability to alternate ocular fixation freely, (5) normal color vision, and (6) absence of diplopia. Subjects with $>4$ diopters of myopia, hyperopia, or astigmatism were excluded. Scotoma mapping was performed with no refractive correction, unless subjects wore contact lenses.

Testing apparatus. Subjects were seated in a dark room with their head stabilized in a chin/forehead rest to minimize head movements while facing a translucent tangent screen at $57 \mathrm{~cm}$. Stimuli were rear-projected onto the screen, which subtended $\pm 53^{\circ}$ horizontally and vertically, using a calibrated digital light projector (Hewlett Packard Model xb31, $60 \mathrm{~Hz}$ refresh rate; Packer et al., 2001). It was controlled with a visual stimulus generator (VSG 2/5; Cambridge Research Systems) using custom software. The projected viewing area was $1024 \times 768$ pixels, with each square pixel $1.42 \mathrm{~mm}$ on a side. Eye position was monitored using a separate infrared $60 \mathrm{~Hz}$ video camera for each eye (iView X; SensoMotoric Instruments). To avoid obstructing the field of view, the cameras were mounted overhead and infrared mirrors were used to image the subject's eyes. Analog voltages representing the $X / Y$ position of each eye, and the location of visual stimuli on the tangent screen were recorded digitally at $120 \mathrm{~Hz}$ for off-line analysis by a Power 1401 data acquisition and control system using Spike 2 software (Cambridge Electronics Design).

Dichoptic stimulus presentation. Subjects wore goggles containing dichroic filters, which transmitted red to the right eye and blue to the left eye. Black rubber lens shades prevented subjects from seeing around the lenses. The dichroic filters (Edmund Optics) matched the spectral transmission properties of the dichroic filters in the digital light projector color wheel. There was $0.092 \%$ transmission of red light through the blue filter and $0.28 \%$ transmission of blue light through the red filter. This "cross talk" was rendered invisible by showing stimuli against a textured background, consisting of a fine purple random dot noise pattern (each element $0.14 \times 0.14^{\circ}$ ) visible to both eyes. A fresh background was generated on presentation of the fixation cross. The background pattern made it impossible for subjects to detect the faint second image that occurred from passage of the wrong color through the dichroic filter. It also helped subjects to maintain their customary angle of exotropia during testing. Without a background, subjects showed more variability in their deviation angle, and even normal subjects with a large phoria experienced separation of the eyes.

Determination of eye choice for target acquisition. To initiate a trial the subject fixated a central cross subtending $1^{\circ}$. It was randomly assigned to be blue, red, or purple (Fig. 1). When the cross was blue or red, the subject fixated with the left or the right eye, respectively. When it was purple (a combination of isoluminant blue and red), the subject could choose either eye. The percentage of purple cross trials initiated with the left eye versus the right eye provided a quantitative index of ocular fixation preference.

After the cross was foveated for a variable interval between 500 and $2000 \mathrm{~ms}$, a $1^{\circ}$ spot was presented in the periphery for $200 \mathrm{~ms}$. It was assigned randomly to be blue, red, or purple. The subject's task was to make a saccade to the peripheral target. By the time the eye reached the target, it had disappeared. This strategy discouraged corrective eye movements following the initial saccade. It also avoided development of any bias in eye choice that might be caused by the target being visible at the end of some saccades (e.g., right eye to a red target) but not others (e.g., right eye to a blue target). To provide feedback to subjects, a reward tone sounded when a saccade landed within $5^{\circ}$ of the target. The next trial began $500 \mathrm{~ms}$ later.

Peripheral targets were presented pseudorandomly at $5^{\circ}$ intervals over a grid measuring $\pm 30^{\circ}$ horizontally and $\pm 15^{\circ}$ vertically. There were 90 points in each grid and nine possible stimulus conditions (blue, red, or purple cross $\times$ blue, red, or purple target). It required 810 trials to test all points and stimulus conditions once. Efficient subjects did $\sim 25$ trials/ min although most subjects, especially children, performed more slowly. If a subject was willing, the test was repeated multiple times to test individual points more than once. Some subjects had difficulty completing even a single complement of test points.

In three subjects, an additional four stimulus conditions were tested. The fixation cross was displaced horizontally by the amount of the subject's ocular deviation to bring the nonfixating eye to the center of the tangent screen. Displacement was accomplished by on-line feedback of each eye's position before trial initiation. This manipulation, performed for some trials displaying a red cross/red target, red cross/blue target, blue cross/blue target, and blue cross/red target, probed the impact of orbital position versus eye of fixation on target acquisition.

Each trial was examined off-line to compile maps of saccade behavior for each combination of cross color and target color. The eye that landed closest to the target was deemed to have acquired it. Saccadic and glissadic corrective movements were infrequent. When they occurred, the eyes' initial position rather than corrected position was plotted. If no eye came within $10^{\circ}$ of the target, or no saccade was made, the trial was not included in the data analysis.

Saccade hypometria data were analyzed by fitting a mixed effect model (McLean et al., 1991), such that:

\section{Undershoot}

$$
=\beta_{1} \text { saccade amplitude }+\beta_{2} \text { saccade amplitude } \times C+\beta_{3} U+\varepsilon,
$$

where $C$ denotes whether the saccade is adducting (1) or abducting ( 0$) ; U$ is a vector of random effects with mean $E(u)=0$ and an unstructured variance-covariance matrix; $\varepsilon$ denotes the random error; and $\beta_{1}, \beta_{2}$, and $\beta_{3}$ are model parameters. To test statistical significance, an $F$ test was performed on the interaction term.

Mapping of suppression scotomas. In 10/16 subjects the organization of suppression scotomas was mapped by dichoptic visual field testing, using methods described previously (Economides et al., 2012). In brief, the procedure was nearly identical to that followed in mapping eye choice for target acquisition, except that subjects were instructed to maintain fixation on the central cross throughout the trial. Instead of making a saccade to the peripheral target, they verbally reported its color. The color of the fixation cross varied randomly between blue and red; the peripheral 
target was either blue, red, or purple. The color reported by the subject for purple targets revealed which eye was suppressed locally in the visual field. For example, if a purple stimulus was reported as "red," the left eye was suppressed at that location. Responses on blue and red trials provided a measure of patient reliability, because they were visible to only one eye, and hence only one color could be declared correctly. Strabismic subjects were not aware that some trials were purple, rather than a single color (blue or red), while performing the test.

Color discrimination becomes more difficult as stimulus distance increases from the fovea. The use of color for dichoptic testing raises the possibility that distance from the fovea could be a confounding factor. For example, subjects might identify a target falling farther from either fovea with more difficulty, simply because of decreased color contrast. The size $\left(1^{\circ}\right)$ and contrast ( $0.5 \log$ units brighter than background) of colored stimuli were sufficient for subjects to perceive them reliably anywhere on the tangent screen. In control experiments reported previously, adult subjects with recent onset of ocular misalignment were tested (Economides et al., 2012). They did not have suppression and therefore experienced diplopia. When presented with a purple target anywhere on the tangent screen, they reported seeing both a red target and a blue target, separated by the amount of their ocular deviation. Accordingly, we interpreted perception of only one color as evidence of suppression in the other eye.

One might have combined mapping of suppression scotomas with mapping of saccadic behavior by having subjects make a saccade to peripheral targets and call out their color at the same time. We did not follow this approach for two reasons. First, the idea of comparing the maps evolved during the course of these experiments. Second, it seemed preferable to gather the maps during independent testing sessions and then to compare the data. Saccades to flashed targets are executed almost reflexively, whereas verbal identification of stimulus color requires some thought.

\section{Results}

Saccades to visual targets were recorded in 16 subjects with a history of exotropia, or outward deviation of the eyes, since early childhood. The subjects had 20/20 visual acuity in each eye, could voluntarily switch fixation between the eyes, and denied diplopia. Trials were initiated by fixating a cross located in the center of a tangent screen (Fig. 1). After a variable delay a target appeared for $200 \mathrm{~ms}$ in the peripheral visual field. The subjects' task was to make a reactive saccade to the target. A red filter was worn over the right eye and a blue filter over the left eye. The color of the central fixation cross and the peripheral target varied randomly between red, blue, and purple.

\section{Target acquisition by the eye exposed to the target}

Figure 2 shows data from a 36-year-old woman with an $18^{\circ}$ exotropia since childhood. When trials began with fixation by the left eye and the peripheral target was visible only to the left eye (blue cross/blue target), the peripheral target was almost always acquired by the left eye (Fig. $2 a$ ). The same was true when stimuli were visible only to the right eye: on such trials (red cross/red target) the target was acquired by the right eye (Fig. 2b).

In exotropia the peripheral temporal retina is suppressed in each eye to prevent diplopia. In this subject the visual fields were mapped dichoptically in a separate experimental session. The perceptual data revealed that red and blue stimuli were detected accurately throughout the visual fields (Fig. $2 c, d$ ). Monocular stimuli are perceived everywhere, despite strabismus, because the phenomenon of suppression is evoked only when stimuli are presented simultaneously to both eyes (Economides et al., 2012). In our testing paradigm, this occurs only on purple target trials.

Comparison of the saccade data (Fig. $2 a, b$ ) and the perceptual data (Fig. $2 c, d$ ) revealed a close match. On nearly all trials, a saccade was executed to bring the eye that perceived the target
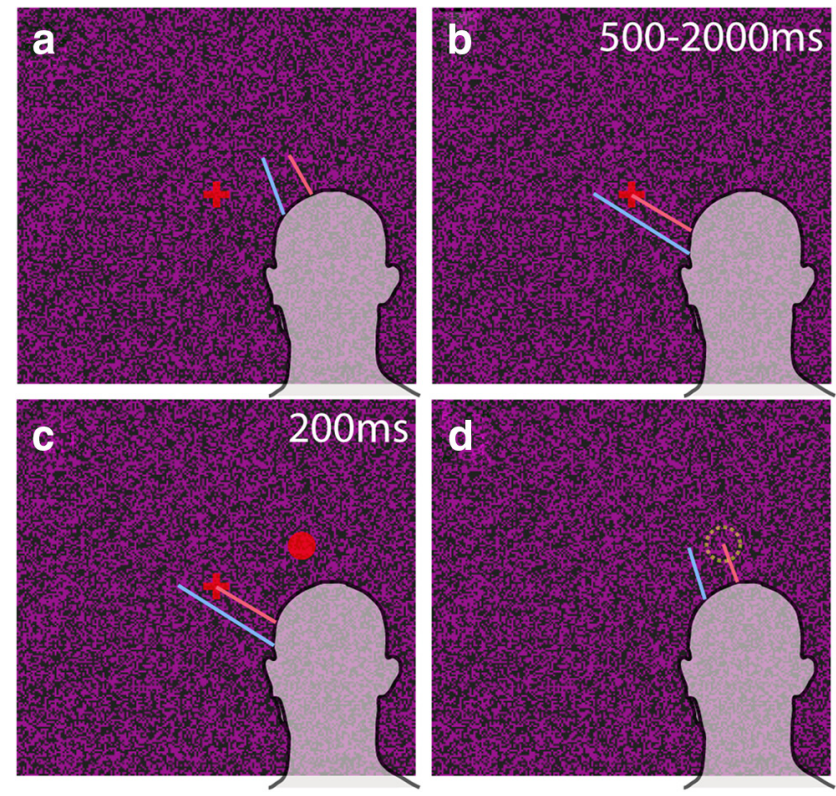

Figure 1. Procedure for determining eye choice for target acquisition in alternating exotropia. $\boldsymbol{a}$, Subject wearing filter glasses (red for right eye, blue for left eye) is seated in the dark while viewing a tangent screen with a textured purple background. A red, blue, or purple cross appears at the center of the screen. $\boldsymbol{b}$, Subject makes a saccade to the central cross and fixates it. c, After steady fixation on the central cross for a variable time period, a red, blue, or purple target appears briefly somewhere in the periphery. $\boldsymbol{d}$, Subject makes a saccade to the peripheral target. It is gone before the eye arrives.

onto it. By chance, on some trials the target landed in the immediate vicinity of the deviated eye. In that situation, the subject would have been credited with acquisition of the target by making just a small eye movement. Nonetheless, she made a large saccade to acquire it with the other eye.

In normal subjects it is typical for saccades to undershoot target position by $\sim 10 \%$ of target eccentricity (Becker and Fuchs, 1969; Weber and Daroff, 1971; Henson, 1978), although the accuracy of saccades is dependent upon many factors, such as the experimental paradigm, testing method, and subject performance (Collewijn et al., 1988; Aitsebaomo and Bedell, 1992; Kowler and Blaser, 1995). In the task performed by our exotropic subjects, it was common for saccades to fall short of their target. The amount of undershoot increased with target distance from the initial fixation point (Fig. 2a,b).

In normal subjects, nasal saccades have a slightly longer duration than temporal saccades, and their velocity is correspondingly slower. However, there is no nasal versus temporal difference in the amount of saccadic hypometria (Robinson, 1964). In contrast, the exotropic subject illustrated in Figure 2 showed a striking asymmetry in horizontal target error, indicated by the length of the vector between eye position and target position. Across all 16 subjects (Fig. 3), adducting saccades were more hypometric than abducting saccades $(p<0.0001)$. For $30^{\circ}$ saccades, the mean undershoot was $5.5^{\circ}(18 \%)$ in adduction and $3.6^{\circ}(12 \%)$ in abduction.

\section{Crossover saccades}

The largest saccades were elicited when the fixation cross and the peripheral target differed in color. On such trials the fixation cross was red and the target was blue, or vice versa (Fig. $4 a, b$ ). The eye exposed to the target commenced the trial in a temporally deviated orbital position. Accordingly, the target could be located 

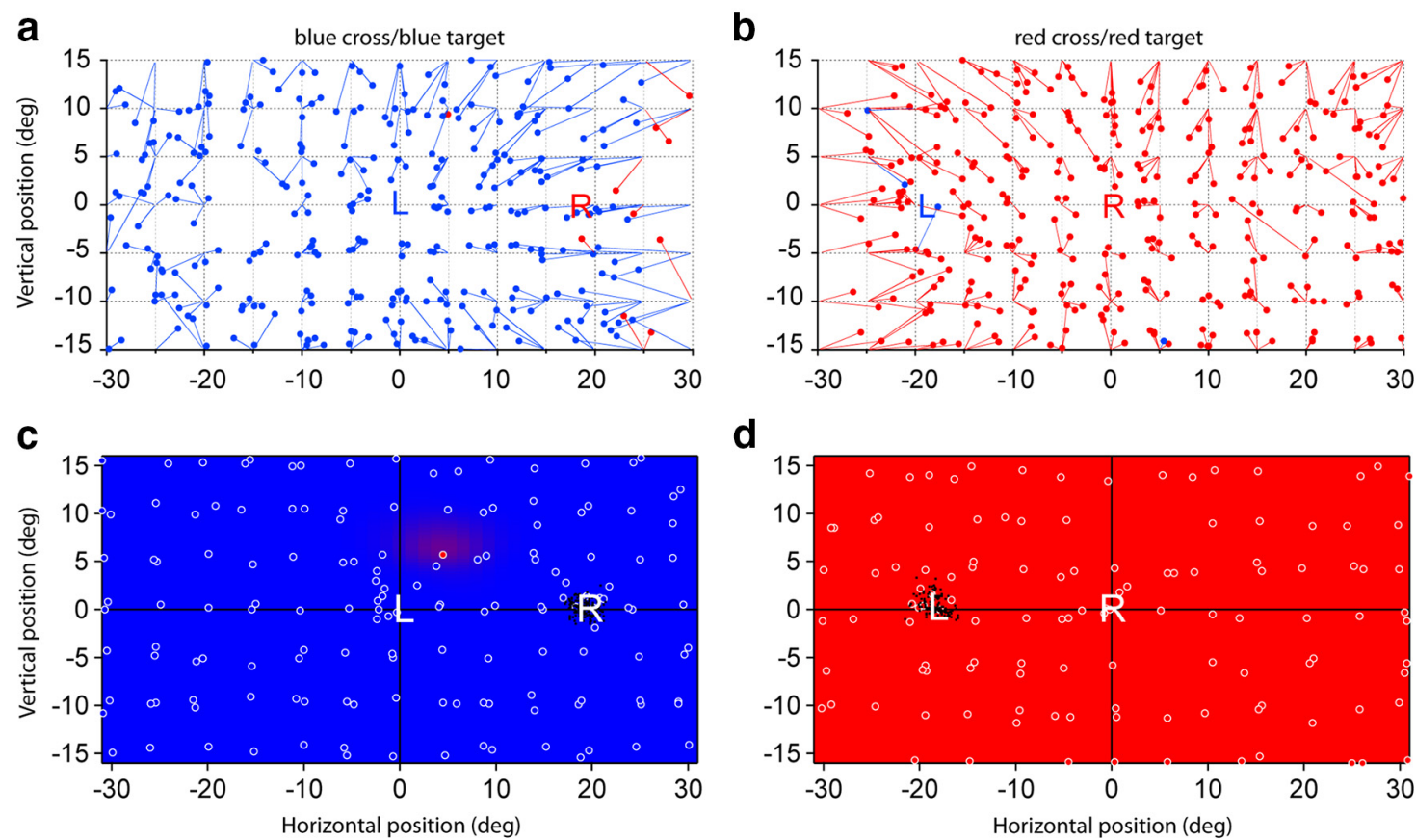

Figure 2. Target acquisition by a 36-year-old subject with alternating exotropia. $\boldsymbol{a}$, Saccade data for blue cross/blue target trials. The targets appeared randomly at interstices of the grid. Red (right eye) or blue (left eye) dots indicate which eye was closest after a target acquisition, with the error indicated by a line to the target location. If neither eye landed within $10^{\circ}$ of the target, $\mathrm{n} 0$ marker is shown (for example, horizontal $30^{\circ}$, vertical $5^{\circ}$ ). $\boldsymbol{b}$, Saccade data for red cross/red target trials. c, Perceptual data for blue cross/blue target trials. The color filling each white circle indicates the subject's verbal report of the target color; shading between circles is a smoothed Kriging interpolation of the data. Jitter in target position reflects a correction for the difference in position between the fixation cross and the fixating eye recorded by the eye tracker. Black dots represent the position of the deviated eye on each trial. $\boldsymbol{d}$, Perceptual data for red cross/red target trials. Note match between the saccade data $(\boldsymbol{a}, \boldsymbol{b})$ and the perceptual data $(\boldsymbol{c}, \boldsymbol{d})$ : for the majority of trials the saccade to the target was made by the eye that detected the target. L (left) and R (right) indicate mean positions of the eyes during central cross fixation.

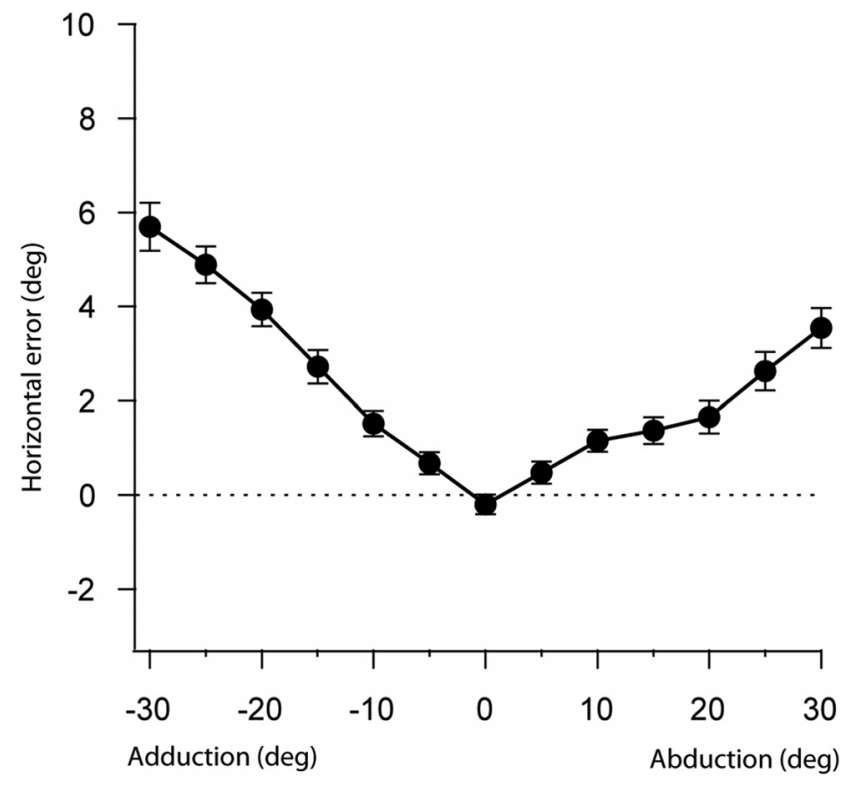

Figure 3. Horizontal error in adducting versus abducting saccades executed by the fixating eye starting at $0^{\circ}$. Each point is the mean error \pm SEM $(n=16$ subjects) for saccades to each horizontal location for the seven $\left( \pm 15^{\circ}\right)$ vertical target coordinates. Adducting saccades were significantly more hypometric than abducting saccades.

nearly $50^{\circ}$ nasal to the deviated eye. On some trials, the subject made a large adducting saccade to acquire the target. On other trials, she appeared to acquire the target with the other eye. This behavior would mean that information about target location was received by one eye but a saccade was programmed to bring the other eye onto the target. We define such events as "crossover" saccades. They permit an exotropic subject to substitute a smaller abducting saccade for a larger adducting saccade.

When the target was located far nasally, it was sometimes ambiguous with which eye the subject actually intended to acquire it. Often the eyes straddled the target when they came to rest. We awarded the target to the closest eye, but this rule did not necessarily reflect the true goal of the eye movement. For example, when there was a large undershoot in one eye and a small overshoot in the other eye, the saccade was credited to the overshooting eye. It is likely, however, that the undershooting eye was actually the one trying to reach the target, because typically saccades are hypometric.

We attempted to referee the crossover saccades on a trial-bytrial basis, based on the eyes' relative landing positions and their trajectories with respect to the target. For red cross/ blue target trials (Fig. $4 a$ ) there were 52 crossover saccades, i.e., the target was seen by the left eye but the right eye landed closer. In many cases it was uncertain which eye was intended to capture the target. In at least 20 cases, however, the subject was judged to make a saccade to the target with the right eye. Sometimes the subject used a different eye for the same target color at a given location. An example is provided by the location at $-10^{\circ}$ horizontal, $+10^{\circ}$ vertical for blue cross/red target trials (Fig. $4 b$ ). On one occasion the subject acquired the red target with the right eye, but on another occasion it seemed clear that she used the left eye (Fig. 5). Comparison of such trials provided the most convincing evidence that crossover saccades are a genuine phenomenon.

Given that many trials were difficult to arbitrate, we decided simply to assign target capture to the nearest eye. This rule exaggerated the frequency of crossover saccades, but had 

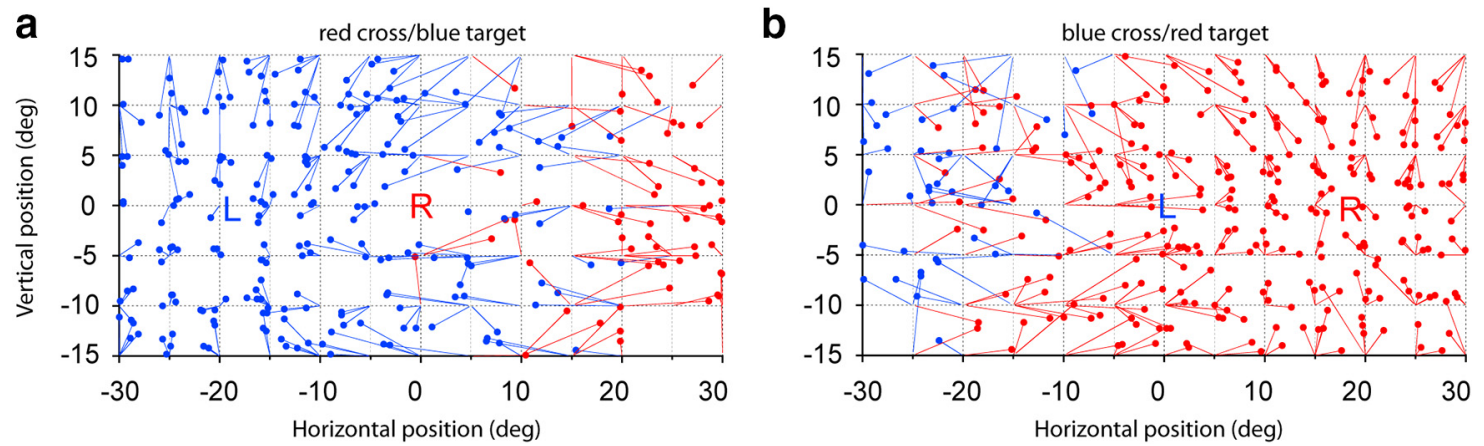

Figure 4. Crossover saccades elicited by a target presented nasally to a temporally deviated eye. $\boldsymbol{a}$, Red cross/blue target trials. $\boldsymbol{b}$, Blue cross/red target trials. The target color is the same as in Figure $2, a$ and $b$, respectively, but the eye to which they are presented is temporally displaced in the orbit by the amount of the ocular deviation $\left(\sim 18^{\circ}\right)$. As a result, the subject often executed a crossover saccade by acquiring the target with the other eye. Crossover saccades are events represented by red circles in $(\boldsymbol{a})$ and blue circles in $(\boldsymbol{b})$.

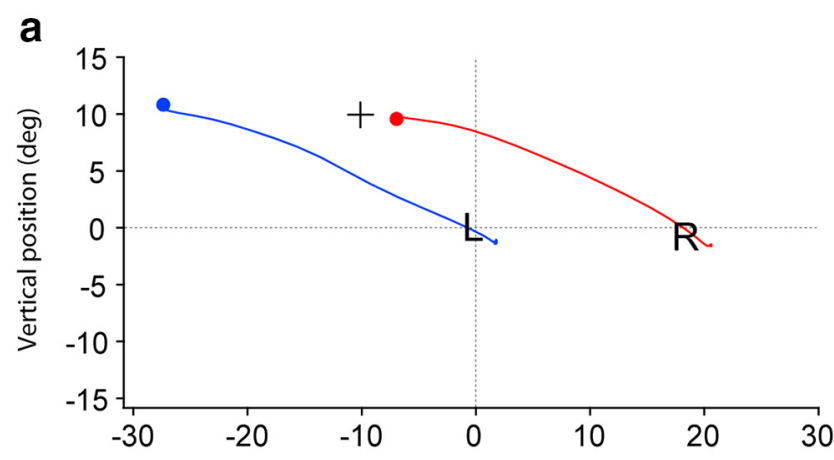

b

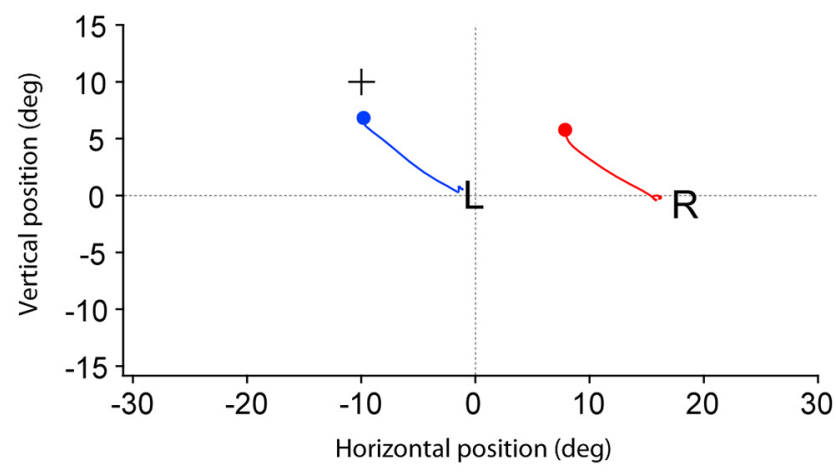

Figure 5. Comparison of two different trials in Figure $4 b$ for a red target located at $-10^{\circ}$ horizontal, $+10^{\circ}$ vertical. $\boldsymbol{a}$, Target acquired by the eye that saw it, namely, the right eye. There was a $3.1^{\circ}$ error. $\boldsymbol{b}$, Target acquired by the eye blind to it, namely, the left eye. There was a $3.2^{\circ}$ error. This trial represents a crossover saccade. Plus sign denotes target location, $L$ (left) and $R$ (right) signify mean initial eye positions for all trials, and blue and red circles indicate final eye positions.

the advantage of providing a single, consistent criterion to identify them.

As mentioned before, crossover saccades were more frequent when the central fixation cross and the peripheral target differed in color and thus were visible to different eyes (compare Fig. $2 a, b$ with $4 a, b$ ). There are two potential explanations for this finding. First, displacing the perceiving eye to a temporal orbital position meant that larger adducting saccades were required to acquire nasal targets. The extra distance alone might encourage more crossover saccades. Second, engaging an eye in fixation of the central cross could make the oculomotor system more likely to program the next saccade for that eye. Accordingly, for example, more crossover saccades might be expected on red cross/blue target trials than on blue cross/blue target trials.
To differentiate between these two possibilities, the fixation cross was displaced horizontally on some trials to bring the nonfixating eye into primary position (Fig. 6). The required displacement averaged $18^{\circ}$, with slight variation from trial to trial, depending on the precise angle of exotropia at any moment. Crossover saccades were infrequent when the filter covering the eye at the center of the tangent screen matched the color of the peripheral target, regardless of which eye fixated the cross to initiate the trial (note similarity between Fig. $2 a, b$ and $6 a, b$ ). By the same token, crossover saccades were common when the eye displaced temporally matched the color of the peripheral target, regardless of which eye fixated the cross to initiate the trial (note similarity between Fig. $4 a, b$ and $6 c, d$ ). These results suggest that eye choice for acquisition of targets, under these artificial testing conditions, is not influenced strongly by which eye is engaged in fixation at the moment the saccade is planned. Rather, the orbital position of the eyes relative to the target is what matters. Similar results were obtained in two other patients tested by displacing the fixation cross temporally.

Figure 7 shows data compiled from all 16 patients. They had a mean deviation of $13.5 \pm 5.3^{\circ}$ (range $5-22^{\circ}$ ). Behavior is compared under two conditions: the eye fixating the central cross perceiving the peripheral target (Fig. $7 a, b$ ) versus the eye displaced temporally perceiving the target (Fig. $7 c, d$ ). With the eye perceiving the target in primary position, crossover saccades occurred on $9.3 \%$ of trials. With the perceiving eye displaced temporally (because the central fixation cross was visible only to the other eye) crossover saccades occurred on $30.6 \%$ of trials. Under both conditions, crossover saccades became common when the target was presented more than $\sim 25^{\circ}$ into the nasal visual hemifield of the perceiving eye. As one would expect, the transition zone shifted on the tangent screen with change in ocular fixation by approximately the amount of the subjects' mean deviation (Fig. 7, compare $a, b$ with $c, d$ ). This supports the idea that crossover saccades occurred whenever the size of the required adducting saccade exceeded a certain limit, averaging $\sim 25^{\circ}$ in our population.

The mean latency of saccades when the target was perceived by the acquiring eye was $227 \pm 62 \mathrm{~ms}(n=6824)$. The mean latency of crossover saccades was $276 \pm 88 \mathrm{~ms}(n=1280)$. The latencies were significantly different $(p<0.0001, Z$ test $)$.

\section{Eye choice for targets presented to both eyes}

On some trials the peripheral target was visible potentially to both eyes (blue cross/purple target or red cross/purple target). Such trials produced a pattern of target acquisitions that differed rad- 
a

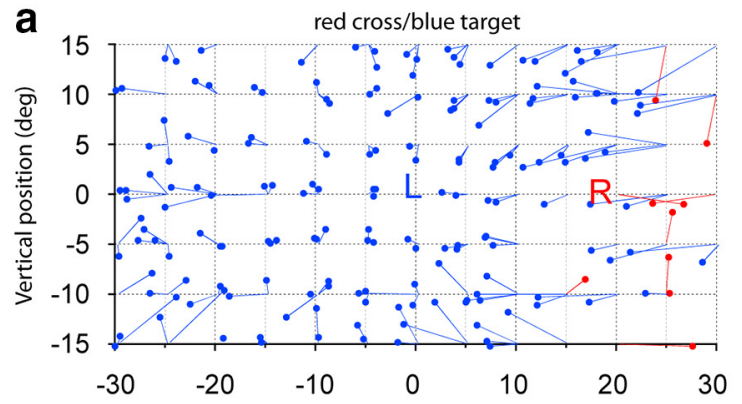

C

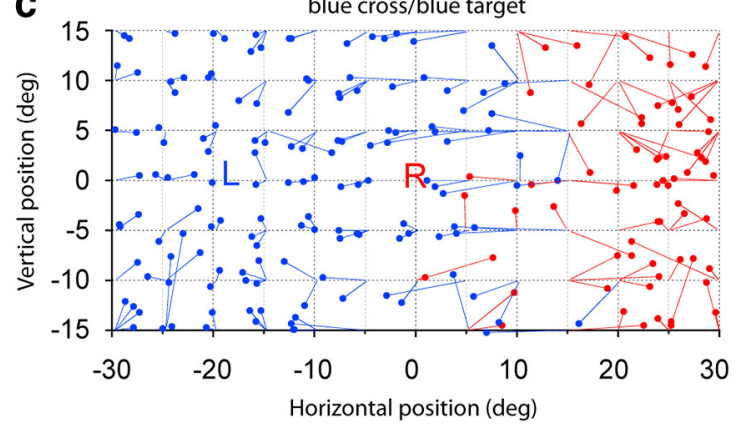

b

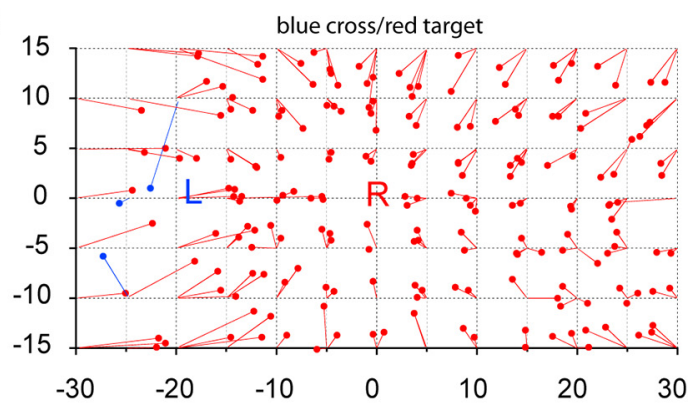

d

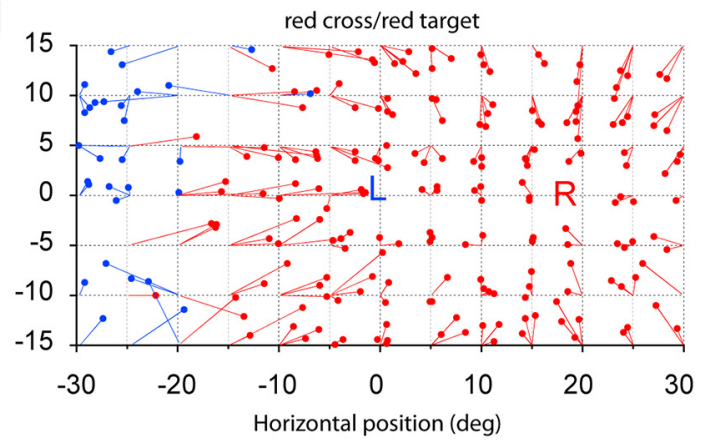

Figure 6. Impact of eye fixation versus orbital position on the frequency of crossover saccades. $\boldsymbol{a}$, Red cross/blue target trials, with the red cross displaced to the right by $\sim 18^{\circ}$ (compare with Fig. 2a). $\boldsymbol{b}$, Blue cross/red target trials, with the blue cross displaced to the left by $\sim 18^{\circ}$ (compare with Fig. 2b). The results in $\boldsymbol{a}$ and $\boldsymbol{b}$ are similar to those in Figure 2 , indicating that which eye fixates the cross to initiate the trial does not influence the occurrence of crossover saccades. $\boldsymbol{c}$, Blue cross/blue target trials, with the blue cross displaced to the left by $\sim 18^{\circ}$ (compare with Fig. $4 a$ ). $\boldsymbol{d}$, Red cross/red target trials with the red cross displaced to the right by $\sim 18^{\circ}$ (compare with Fig. $4 b$ ). The results in $\boldsymbol{c}$ and $\boldsymbol{d}$ are similar to those in Figure 4 , confirming that the frequency of crossover saccades does not depend on which eye fixates the cross at the beginning of the trial. Instead, the critical factor is the distance of the target from the fovea of the perceiving eye. Shifting the perceiving eye temporally causes more targets on the tangent screen to be captured by the other eye.
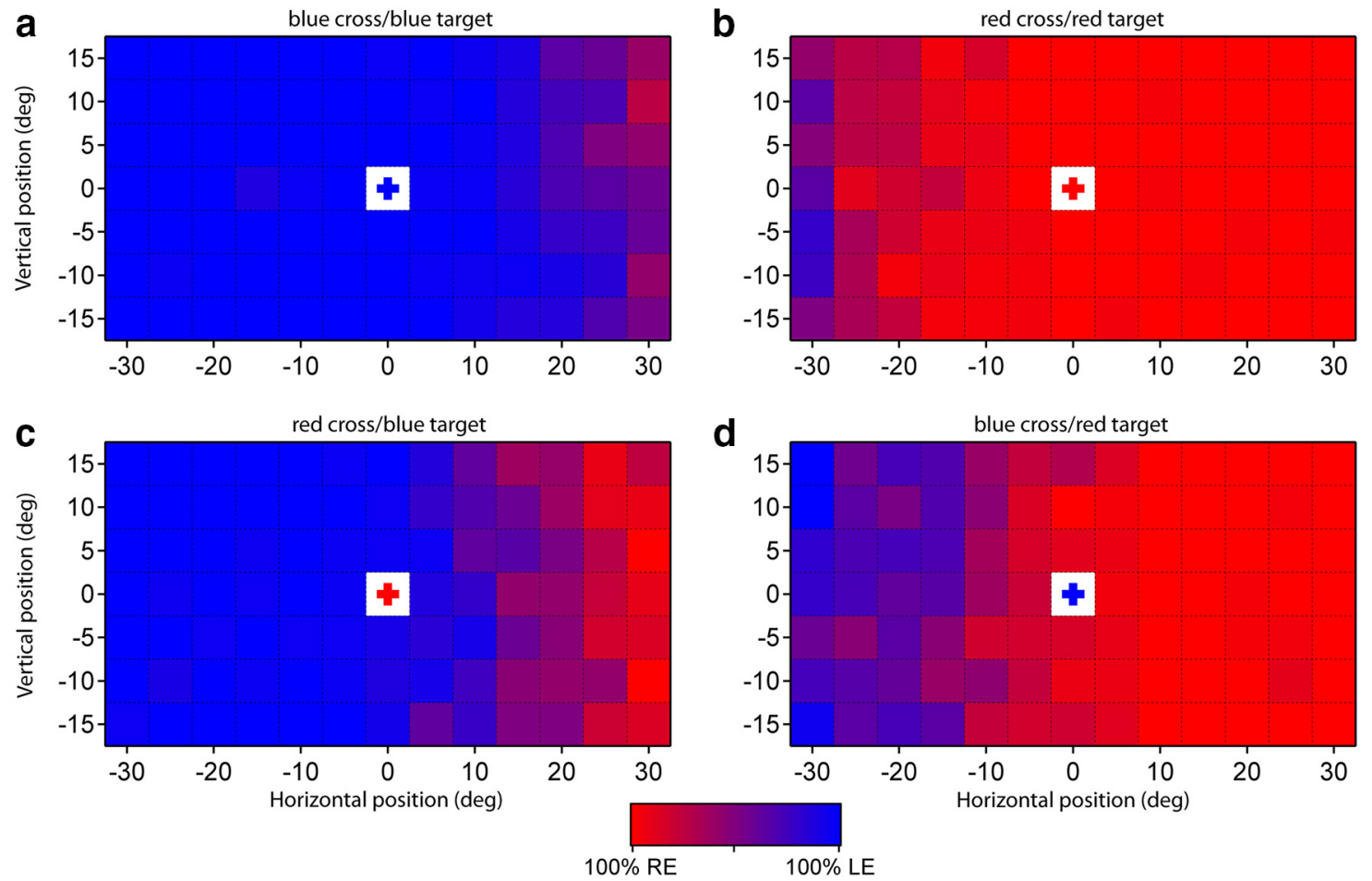

d

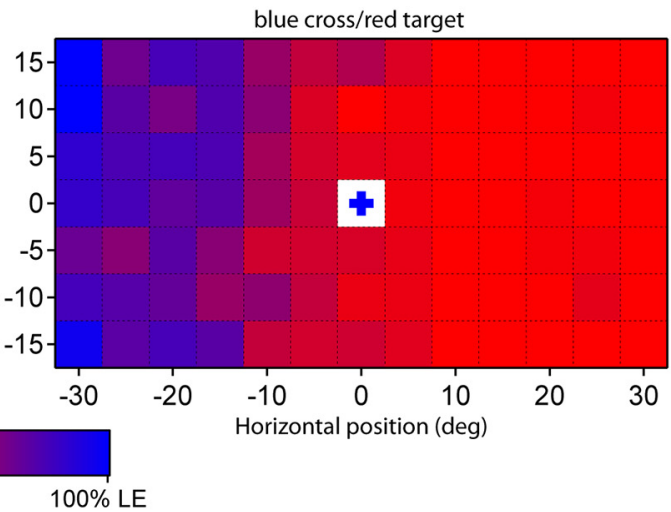

Figure 7. Target acquisition on 8104 trials by 16 subjects. $\boldsymbol{a}, \boldsymbol{b}$, Blue cross/blue target and red cross/red target trials. Color shading of bins indicates the percentage of targets acquired by the right eye (RE) and left eye (LE). Crossover saccades are confined to the far nasal field because the perceiving eye is situated at the center of the tangent screen. This limits the requirement for adducting saccades to a maximum of $30^{\circ} . \boldsymbol{c}, \boldsymbol{d}$, Red cross/blue target and blue cross/red target trials. Crossover saccades are more common, because the eye that can see the target is positioned more temporally. The shift in the spatial prevalence of crossover saccades from top to bottom panels corresponds to the subjects' mean ocular deviation $\left(13.5^{\circ}\right)$, with some smearing because of variation in strabismus angle among subjects. 
a

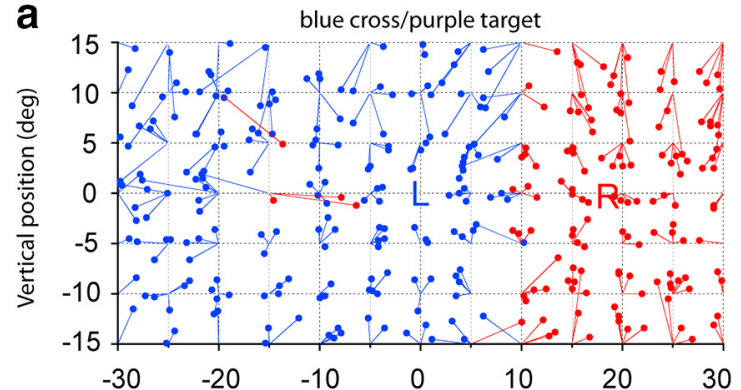

C

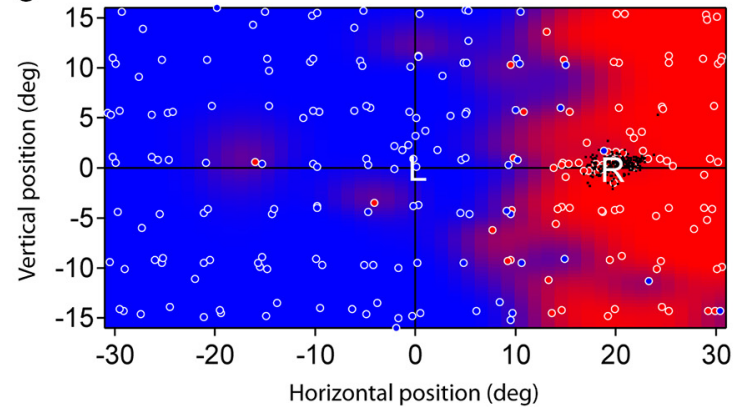

b

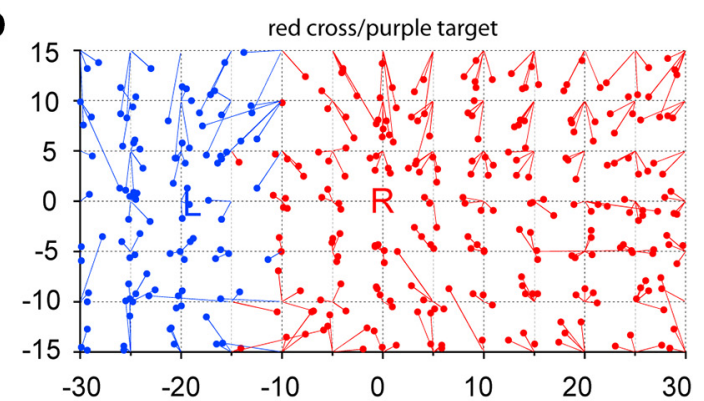

d

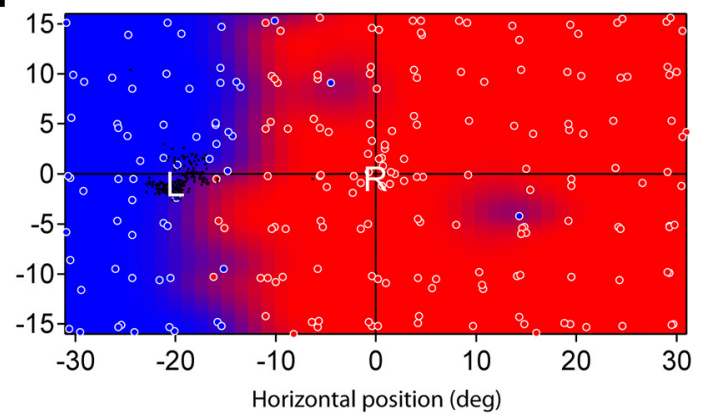

Figure 8. Saccades to targets presented to both eyes. $\boldsymbol{a}, \boldsymbol{b}$, Blue cross/purple target and red cross/purple target trials. A purple target elicits a different pattern of saccadic behavior than a blue (Fig. $2 a$ ) or a red (Fig. 2b) target. There are separate zones where either the left eye or the right eye makes a saccade to the target. $\boldsymbol{c}, \boldsymbol{d}$, Perceptual data for blue cross/purple target and red cross/purple target trials acquired in a separate experiment, showing the patient's verbal identification of target color. In regions shaded blue the right eye is suppressed, and vice versa. Correlation between saccade data and perceptual data implies that saccades are made to each target with the eye that perceives the target.

ically from the behavior elicited when the peripheral target was visible only to the eye initiating the trial. In the latter case, the eye that was fixating the central cross acquired virtually all the peripheral targets (Fig. 2a,b). In distinction, when the target was purple, the eyes divided target acquisition into two zones, separated by a vertical border between their fixation points (Fig. $8 a, b)$.

In a separate session, the subject's perceptual responses to blue cross/purple target and red cross/purple target trials were recorded to determine the layout of the suppression scotomas in her visual fields (Fig. $8 c, d$ ). The maps revealed a vertical border between the center of gaze for each eye, splitting the tangent screen into regions where perception was mediated by either the right eye or the left eye (Economides et al., 2012). In regions where one eye was perceptually dominant, the other eye was suppressed. The perceptual maps and the saccade maps corresponded, indicating that the eye via which the stimulus was perceived was the eye that acquired it during the saccade task.

Dichoptic sensory testing was performed in nine additional subjects with childhood exotropia to allow comparison with the pattern of eye choice for acquisition of purple targets (Fig. 9).

There was a consistent organization of suppression scotomas, with each eye dominant in its temporal visual field. Midway between the center of gaze for each eye, a transition occurred between perception and suppression. Overlay of the saccade behavior elicited during a separate experiment revealed that the left eye tended to acquire binocular (purple) targets in regions where the right eye was suppressed, and vice versa. Some of the apparent exceptions were due to subjects' blind spots. Other exceptions may have been due to variability in the position of the deviated eye from trial to trial.

\section{Eye preference and fixation behavior}

Although our subjects could alternate fixation and had normal acuity in each eye, they exhibited a strong preference to fixate with a given eye. When the central cross was purple, subjects were free to fixate it with either eye. The 16 subjects initiated a mean of $78 \%$ of trials with the same eye. Only one subject started $<60 \%$ of the trials with the same eye.

For example, the subject in Figure 10 fixated with the right eye on $94 \%$ of trials that began with a purple cross. Consequently, behavior on purple cross/red target trials (Fig. 10a) closely resembled red cross/red target trials (Fig. 2b). By the same token, purple cross/blue target trials (Fig. 10b) matched red cross/blue target trials (Fig. 4a) and purple cross/purple trials (Fig. 10c) matched red cross/purple target trials (Fig. $8 b$ ). The subject's strong preference for fixation of the central cross by the right eye did not influence the choice of which eye she used subsequently to acquire peripheral targets. For purple targets, that choice appeared to be determined solely by which eye detected it (Fig. 8).

One might wonder why so many fixation crosses visible to both eyes were acquired by the right eye, given that the preceding trial often ended with the eyes in right gaze. In that situation the purple cross should have appeared blue, and hence visible only to the left eye, because it was located in a right eye suppression scotoma (Fig. $8 c$ ). There were two likely explanations. First, the subject quickly learned to bring her right eye back to the center of the screen during the $500 \mathrm{~ms}$ pause between trials, in anticipation of the next trial. Second, she sometimes fixated the purple cross with the left eye, and then switched spontaneously to the right eye. Fixation of the cross was credited to the eye foveating it at the moment the target appeared in the periphery, so such trials were awarded to the right eye.

\section{Discussion}

When in a diverged state, people with intermittent exotropia occasionally alternate fixation by switching from one eye to the other to explore interesting features in the visual scene. This behavior can give rise to confusion in social interactions because interlocutors are unsure to whom attention is being directed (Babar et al., 2010). The proclivity to alternate fixation is one 

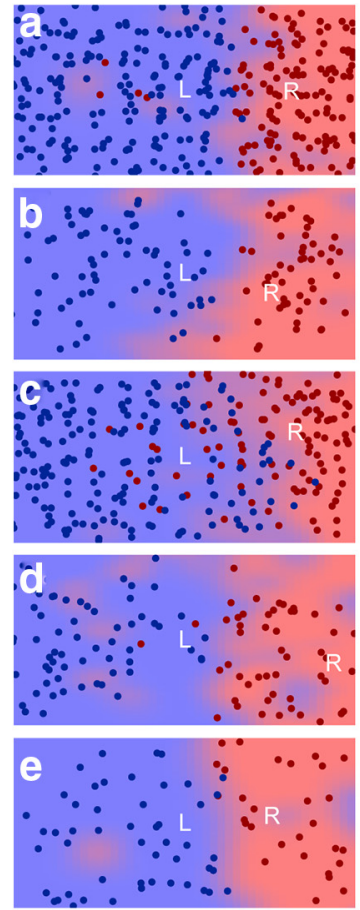
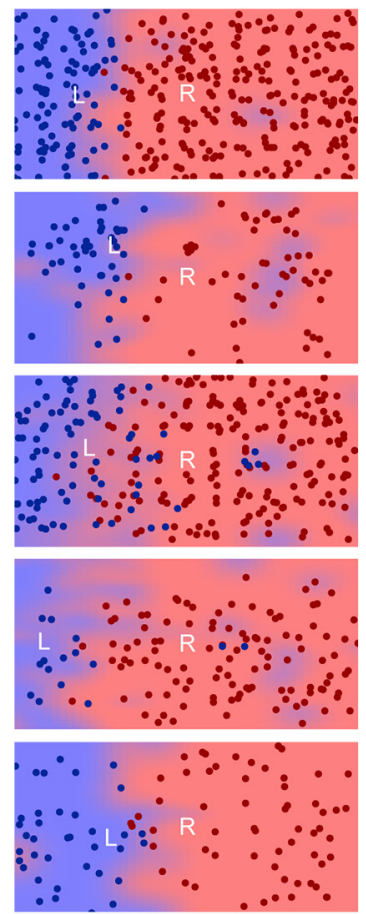
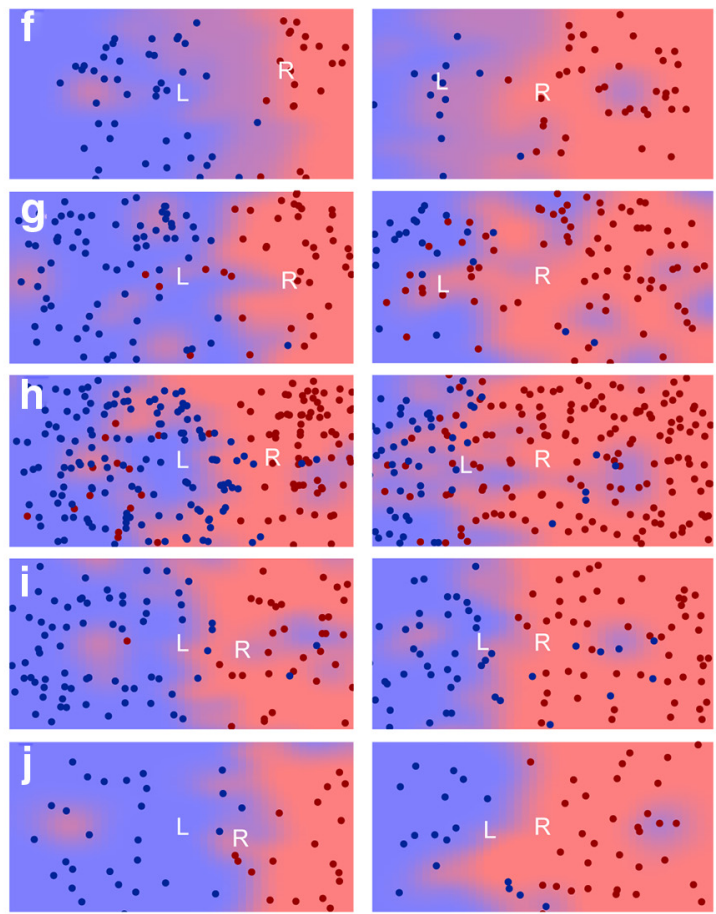

Figure 9. Correlation between perceptual maps and fixation behavior in 10 strabismic subjects $(\boldsymbol{a}-\boldsymbol{j})$. Each set of plots shows responses with the left eye (L) fixating centrally and the right eye (R) fixating centrally. Blue shading indicates regions where purple stimuli were perceived with the left eye, and red shading denotes perception with the right eye (see Economides et al., 2012, Fig. 6, for further explanation). The dots overlaid on the perceptual maps indicate the landing points of saccades made to purple targets by either the left eye (blue dots) or the right eye (red dots) during a separate experiment. On most trials, targets seen by the left eye were acquired by the left eye, and vice versa. Subject $a$ is featured in Figures $2,4-6,8$, and 10 . The position shown for the deviated eye is an average of all trials: there was considerable trial-to-trial variability.

reason why amblyopia is uncommon in intermittent exotropia (Cotter et al., 2009). The other reason is that decompensation usually occurs after the critical period for development of normal acuity in each eye (Kiorpes and Movshon, 1996).

It has been unknown how subjects with intermittent exotropia decide which eye to use to look at a given target or how they make an accurate saccade to a fresh target with one eye when the other eye is fixating elsewhere. The problem is compounded by the fact that exotropic subjects are always viewing two targets at any moment. It can be difficult to know which object is the principal target.

In a previous study, we devised a task for monkeys with alternating exotropia that required them to fixate a central target and then to make a saccade to a target that appeared randomly in the periphery (Economides et al., 2007). The fraction of central targets acquired by each eye reflected the strength of ocular fixation preference. The pattern of saccades to peripheral targets provided a map of saccadic behavior. A sharp vertical border divided the scene into regions where peripheral targets were acquired either by the left eye or the right eye. Das (2009) has tested exotropic monkeys using a similar paradigm, except that the animals in his experiments were not required to fixate centrally at the beginning of each trial. Our data are in good agreement: if a given target lands on the temporal retina in one eye and the nasal retina in the other eye, the eye that received nasal retinal stimulation will usually acquire it (Agaoglu et al., 2014).

The present study was designed to explain this predictable pattern of eye choice for target acquisition in exotropia by linking oculomotor behavior to visual perception. Targets were presented dichoptically, so that they were visible to either the fixating eye, the deviating eye, or to both eyes. There were three main findings. First, if a target is presented to only one eye, that eye will make the saccade to the target. That is true, even if the person has a strong fixation preference for the other eye. The allegiance to the eye stimulated by the target is so powerful that the eye is used to make saccades to locations where, during binocular stimulation, the other eye would normally engage targets (compare Figs. $2,8)$. It is hazardous to infer motive, but the simplest interpretation of this behavior is that the easiest computation for the oculomotor system is to program a saccade for the eye that supplied information about the target's location.

Second, there is an exception to the first finding. When the required saccade is large and adducting, subjects sometimes acquire the target with the other eye (Fig. 4). This strategy allows subjects to avoid making large adducting saccades, which in exotropia tend to undershoot more than abducting saccades (Fig. 3). The reason for the greater inaccuracy of adducting saccades is unclear, but one explanation is that exotropes have less practice making them because sometimes they switch fixation to the other eye. Alternatively, weak adduction tone may be a causative factor contributing to the occurrence of intermittent exotropia. In either case, the ability to make crossover saccades demonstrates that in alternating exotropia the oculomotor system can obtain information about target location from one eye and program a saccade to the target for the other eye. This observation implies that the oculomotor system actively samples information about the position of the deviating eye, not just the fixating eye, to perform this calculation. This might be supplied by proprioceptive feedback from the eye muscles, anomalous retinal correspondence, or central encoding of the strabismus angle (Hallden, 1982; Cooper and Record, 1986; Grant and Berman, 1991; Herzau, 1996; Wong et al., 2000; Wang et al., 2007; Das, 2011).

In exotropic monkeys, Das (2009) has shown that the latency of saccades that involve the same eye or a fixation swap is not 

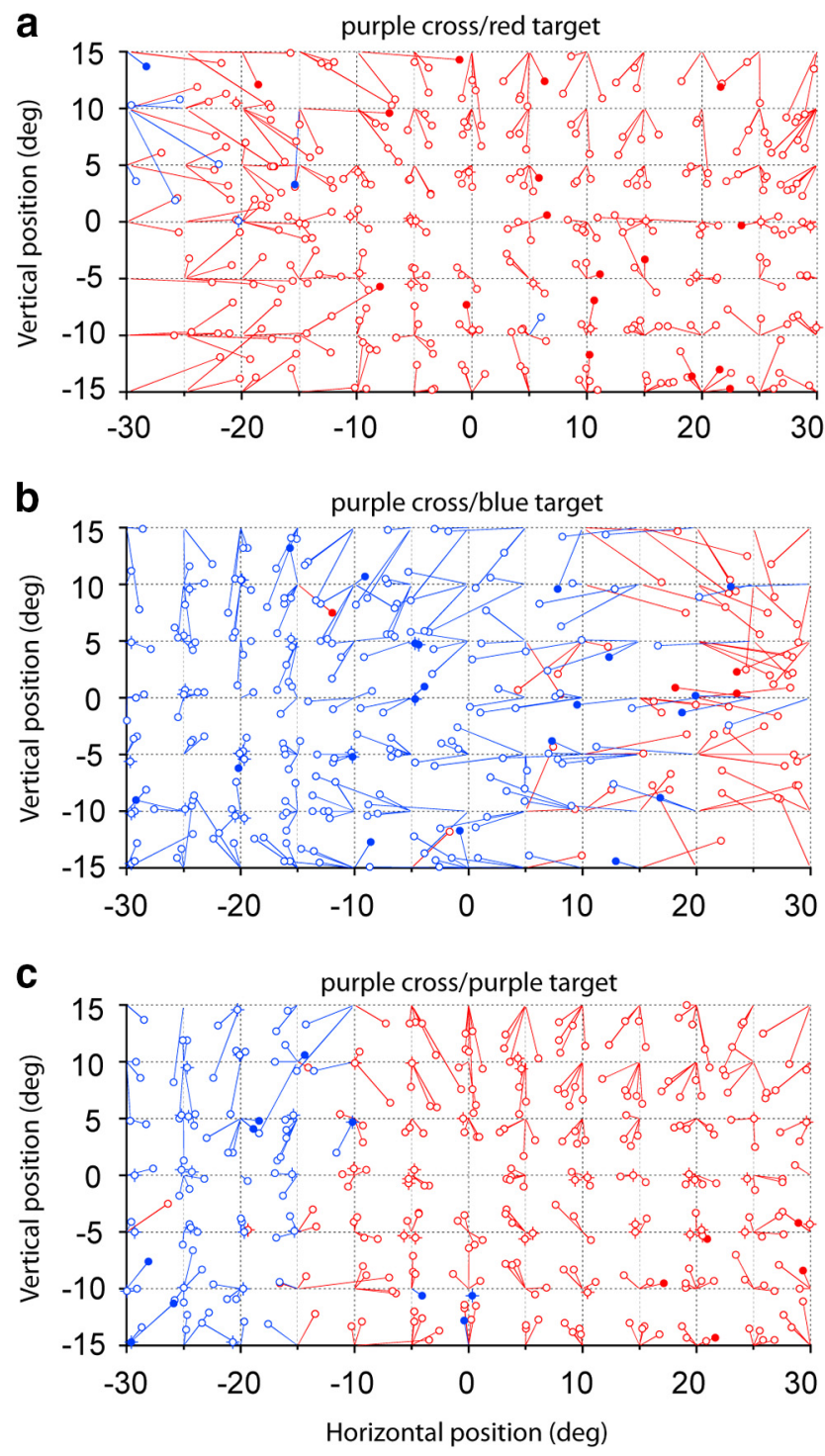

Figure 10. Eye preference for trial initiation. $\boldsymbol{a}$, Purple cross/red target trials. Open circles (93\%) denote trials initiated by fixating the purple cross with the right eye; closed circles (7\%) represent trials started by fixating it with the left eye. Pattern of target acquisitions is similar to that shown in Figure $2 b$, because $93 \%$ of trials were equivalent to red cross/red target trials. $\boldsymbol{b}$, Purple cross/blue target trials, again with $93 \%$ initiated by fixation with the right eye, giving results similar to red cross/blue target trials in Figure 4a.c, Purple cross/purple target trials, with $95 \%$ initiated by right eye fixation. Results are similar to red cross/purple target trials shown in Figure $8 b$. The subject acquired peripheral targets with the eye that perceived them, despite a strong right eye fixation preference, except for the crossover saccades in $\boldsymbol{b}$.

consistently different. In his experiments the target was visible to both eyes. We measured the latency of saccades to targets presented to only one eye. Crossover saccades (target invisible to the acquiring eye) had a latency nearly $50 \mathrm{~ms}$ longer than same eye saccades (target visible to the acquiring eye). This difference suggests that it takes extra time for the oculomotor system to transform the retinal error from the perceiving eye into a motor command that yields an appropriate saccade for the other eye. The increased latency we measured was reasonable in duration for such a computation. A somewhat analogous example is afforded by the antisaccade task, wherein subjects are cued to look in a direction opposite to a target (Antoniades et al., 2013). This maneuver increases saccadic latency by 20-80 ms (Hallett and Adams, 1980).

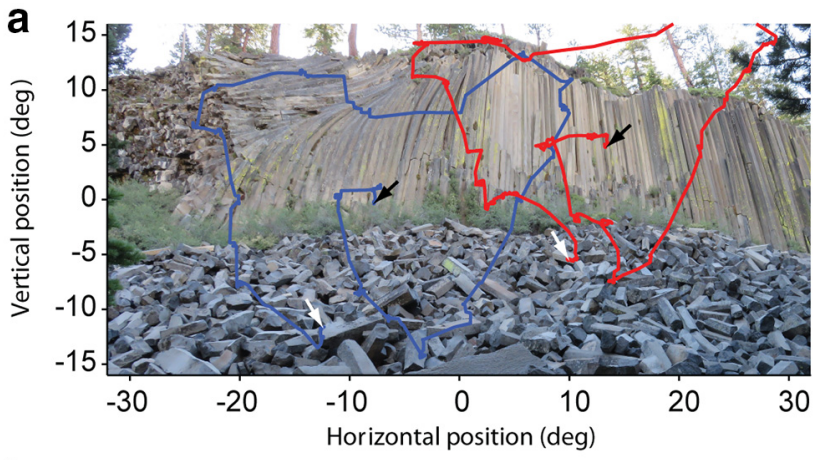

b

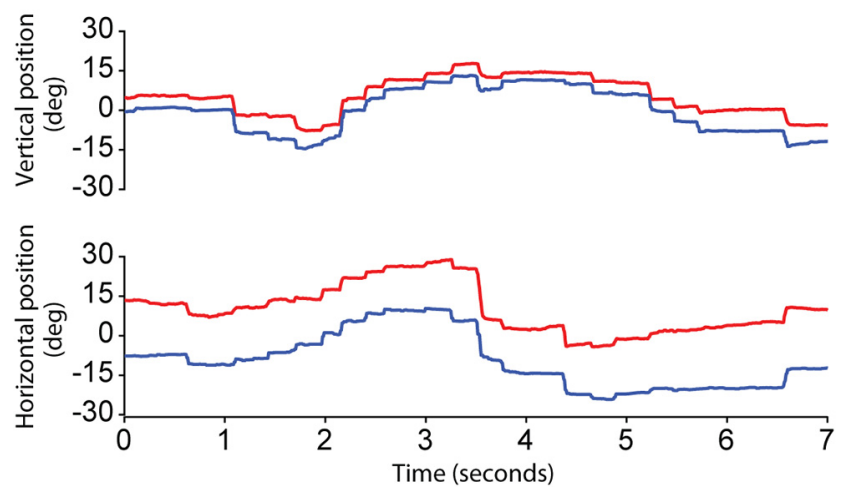

Figure 11. Dual scan paths in strabismus reveal how subjects explore visual scenes. $\boldsymbol{a}, \mathrm{Scan}$ path for the left eye (blue) and the right eye (red) of a 32 -year-old woman with $20^{\circ}$ of alternating exotropia (Fig. 9, subject $c$; note right hypertropia with left eye fixation, and vice versa). During the $7 \mathrm{~s}$ she viewed the image, there were 20 saccades from the start (black arrows) to the end (white arrows). $\boldsymbol{b}$, Vertical and horizontal position traces for the scan path. The mean amplitude of the horizontal component of the saccades was $3.8^{\circ}$. There was a constant right hypertropia, signaling that the left eye was always engaged in fixation, although both eyes contributed to perception of the scene.

It is unknown what neural pathways allow an exotropic subject to make a crossover saccade. Normally, a saccade target evokes sensory and motor activity at the same location in the superior colliculus, albeit in different layers (Schiller, 1984; Gandhi and Katnani, 2011). In strabismus one predicts that when a crossover saccade occurs, a target evokes neuronal activity at one location in the sensory map but activity occurs subsequently at a different location in the saccade direction/amplitude map. Recordings are underway in behaving monkeys raised with exotropia to explore this process.

The third finding from this study was that when a target is presented to both eyes there is a correspondence between each subject's suppression scotoma maps and eye choice maps for target acquisition (Figs. 8, 9). This means that when a scene is viewed binocularly by an alternating exotrope, separate portions of the scene are perceived via each eye and targets are acquired based on information provided directly by the eye that has detected them. Crossover saccades are rare under binocular conditions, because a transfer of target information from perceiving eye to acquiring eye is not necessary. Instead, targets in the far nasal visual field of each eye are perceived by the fellow eye, which can easily acquire them. This results in the occasional, large fixation swaps that are characteristic of exotropic subjects.

In a sense the eye choice maps for target acquisition in Figure 9 are misleading, because they suggest that exotropic subjects confronting a visual scene always make saccades to the left half with the left eye and to the right half with the right eye. This is 
true, but only under artificial conditions, where one eye is forced to fixate centrally while a single target flashes into view somewhere in the periphery. This paradigm does not reflect the way exotropic subjects freely view natural visual scenes with their eyes. Figure 11 shows the scan path for each eye of an exotropic subject (Fig. 9c) with a left eye fixation preference, recorded while she looked at a picture of a cliff face. Although the eyes are deviated, one should bear in mind that information emanating from both foveae is perceived. The peripheral temporal retina in each eye is suppressed but the fovea is spared, even in the deviated eye (Economides et al., 2012). Visual confusion is avoided by anomalous retinal correspondence, whereby points on the deviated eye's retina are shifted peripherally in a head- or body-centered reference frame by an amount equal to the angle of globe misalignment. Information is perceived via the deviated eye's fovea, but not processed on par with the fixating eye's fovea. The effective center of gaze remains associated with the fovea dominated by the subject's visual attention, which is used moment by moment to make saccades to targets.

In strabismus, with two separate scan paths, it is difficult to deduce which fovea is the master and which is the slave during exploration of a scene. Sometimes one can guess, based on which eye is directed toward the most salient features in the image. The subject in Figure 11 exhibited an anomaly that occurs occasionally in exotropia (Das and Mustari, 2007; Walton et al., 2014). When fixating with either eye, the other became slightly elevated (Fig. 9c). During the entire scan path her right eye was hypertropic, by a mean of $5.2^{\circ}$. The right hypertropia revealed that her dominant left eye drove scrutiny of this visual scene. Suppression scotoma mapping showed that the left eye was perceptually dominant for $10^{\circ}$ into its right (nasal) field (Fig. 9c). During free viewing, no rightward saccade by the left eye was $>5^{\circ}$ in horizontal amplitude (Fig. 11). Because only small rightward saccades were made, all targets fell within a zone $10^{\circ}$ nasal to the left eye's center of gaze, where the left eye was perceptually dominant and the right eye was suppressed. As alluded to earlier, strabismic subjects prefer to perceive and saccade with the same eye to targets. This experiment suggests that exotropic subjects explore scenes with their dominant eye, stepping their way with small saccades when they look nasally, to avoid having to switch fixation to the other eye. Head movements, which we have ignored in this study, also occur to avoid large saccades (Guitton, 1992). Alternating saccades are used on an occasional basis, when it is necessary to shift the focus of exploration abruptly to the other side of the scene.

By displaying stimuli to one eye or both, these experiments have allowed us to tease apart the strategies that subjects with alternating exotropia use to make saccades to targets. The oculomotor system adapts remarkably well to misalignment of the eyes. It would be worthwhile to examine other forms of strabismus, such as esotropia with cross fixation, using similar methods.

\section{References}

Adams DL, Economides JR, Sincich LC, Horton JC (2013) Cortical metabolic activity matches the pattern of visual suppression in strabismus. J Neurosci 33:3752-3759. CrossRef Medline

Agaoglu MN, LeSage SK, Joshi AC, Das VE (2014) Spatial patterns of fixation-switch behavior in strabismic monkeys. Invest Ophthalmol Vis Sci 55:1259-1268. CrossRef Medline

Aitsebaomo AP, Bedell HE (1992) Psychophysical and saccadic information about direction for briefly presented visual targets. Vision Res 32:17291737. CrossRef Medline

Antoniades C, Ettinger U, Gaymard B, Gilchrist I, Kristjánsson A, Kennard C, John Leigh R, Noorani I, Pouget P, Smyrnis N, Tarnowski A, Zee DS,
Carpenter RH (2013) An internationally standardised antisaccade protocol. Vision Res 84:1-5. CrossRef Medline

Babar S, Khare GD, Vaswani RS, Irsch K, Mattheu JS, Walsh L, Guyton DL (2010) Eye dominance and the mechanisms of eye contact. J AAPOS 14:52-57. CrossRef Medline

Basso MA, Wurtz RH (1998) Modulation of neuronal activity in superior colliculus by changes in target probability. J Neurosci 18:7519-7534. Medline

Becker W, Fuchs AF (1969) Further properties of the human saccadic system: eye movements and correction saccades with and without visual fixation points. Vision Res 9:1247-1258. CrossRef Medline

Buck D, Powell CJ, Sloper JJ, Taylor R, Tiffin P, Clarke MP, Improving Outcomes in Intermittent Exotropia Study g (2012) Surgical intervention in childhood intermittent exotropia: current practice and clinical outcomes from an observational cohort study. Br J Ophthalmol 96:1291-1295. CrossRef Medline

Burr DC, Morrone MC (2012) Constructing stable spatial maps of the world. Perception 41:1355-1372. CrossRef Medline

Buswell GT (1935) How people look at pictures. Chicago: University of Chicago.

Chia A, Roy L, Seenyen L (2007) Comitant horizontal strabismus: an Asian perspective. Br J Ophthalmol 91:1337-1340. CrossRef Medline

Choi YM, Kim SH (2013) Comparison of clinical features between two different types of exotropia before 12 months of age based on stereopsis outcome. Ophthalmology 120:3-7. CrossRef Medline

Collewijn H, Erkelens CJ, Steinman RM (1988) Binocular co-ordination of human vertical saccadic eye movements. J Physiol 404:183-197. Medline

Cooper J, Feldman J (1979) Panoramic viewing, visual acuity of the deviating eye, and anomalous retinal correspondence in the intermittent exotrope of the divergence excess type. Am J Optom Physiol Opt 56:422-429. CrossRef Medline

Cooper J, Record CD (1986) Suppression and retinal correspondence in intermittent exotropia. Br J Ophthalmol 70:673-676. CrossRef Medline

Cotter SA, Tarczy-Hornoch K, Song E, Lin J, Borchert M, Azen SP, Varma R (2009) Fixation preference and visual acuity testing in a populationbased cohort of preschool children with amblyopia risk factors. Ophthalmology 116:145-153. CrossRef Medline

Das VE (2009) Alternating fixation and saccade behavior in nonhuman primates with alternating occlusion-induced exotropia. Invest Ophthalmol Vis Sci 50:3703-3710. CrossRef Medline

Das VE (2011) Cells in the supraoculomotor area in monkeys with strabismus show activity related to the strabismus angle. Ann N Y Acad Sci 1233:85-90. CrossRef Medline

Das VE, Mustari MJ (2007) Correlation of cross-axis eye movements and motoneuron activity in non-human primates with " $A$ " pattern strabismus. Invest Ophthalmol Vis Sci 48:665-674. CrossRef Medline

Dodge R (1919) Five types of eye movement in the horizontal meridian plane of the field of regard. Am J Physiol 8:307-329.

Economides JR, Adams DL, Jocson CM, Horton JC (2007) Ocular motor behavior in macaques with surgical exotropia. J Neurophysiol 98:34113422. CrossRef Medline

Economides JR, Adams DL, Horton JC (2012) Perception via the deviated eye in strabismus. J Neurosci 32:10286-10295. CrossRef Medline

Eibschitz-Tsimhoni M, Archer SM, Furr BA, Del Monte MA (2007) Current concepts in the management of concomitant exodeviations. Compr Ophthalmol Update 8:213-223. Medline

Gandhi NJ, Katnani HA (2011) Motor functions of the superior colliculus. Annu Rev Neurosci 34:205-231. CrossRef Medline

Grant S, Berman NE (1991) Mechanism of anomalous retinal correspondence: maintenance of binocularity with alteration of receptive-field position in the lateral suprasylvian (LS) visual area of strabismic cats. Vis Neurosci 7:259-281. CrossRef Medline

Guitton D (1992) Control of eye-head coordination during orienting gaze shifts. Trends Neurosci 15:174-179. CrossRef Medline

Hall NJ, Colby CL (2011) Remapping for visual stability. Philos Trans R Soc Lond B Biol Sci 366:528-539. CrossRef Medline

Hallden U (1982) Suppression scotomata in concomitant strabismus with harmonious anomalous correspondence. Acta Ophthalmol 60:828-834.

Hallett PE, Adams BD (1980) The predictability of saccadic latency in a novel voluntary oculomotor task. Vision Res 20:329-339. CrossRef Medline 
Hatt SR, Mohney BG, Leske DA, Holmes JM (2008) Variability of control in intermittent exotropia. Ophthalmology 115:371-376.e2. CrossRef Medline

Henson DB (1978) Corrective saccades: effects of altering visual feedback. Vision Res 18:63-67. CrossRef Medline

Herzau V (1980) Untersuchungen Über Das Binokulare Gesichtsfeld Schielender. Doc Ophthalmol 49:221-284. CrossRef Medline

Herzau V (1996) How useful is anomalous correspondence? Eye 10:266269. CrossRef Medline

Hoyt CS, Pesic A (2012) The many enigmas of intermittent exotropia. Br J Ophthalmol 96:1280-1282. CrossRef Medline

Hunter DG, Kelly JB, Buffenn AN, Ellis FJ (2001) Long-term outcome of uncomplicated infantile exotropia. J AAPOS 5:352-356. CrossRef Medline

Joosse MV, Simonsz HJ, van Minderhout EM, Mulder PG, de Jong PT (1999) Quantitative visual fields under binocular viewing conditions in primary and consecutive divergent strabismus. Graefes Arch Clin Exp Ophthalmol 237:535-545. CrossRef Medline

Kayser C, Nielsen KJ, Logothetis NK (2006) Fixations in natural scenes: interaction of image structure and image content. Vision Res 46:25352545. CrossRef Medline

Kiorpes L, Movshon JA (1996) Amblyopia: a developmental disorder of the central visual pathways. Cold Spring Harb Symp Quant Biol 61:39-48. CrossRef Medline

Kowler E (2011) Eye movements: the past 25 years. Vision Res 51:14571483. CrossRef Medline

Kowler E, Blaser E (1995) The accuracy and precision of saccades to small and large targets. Vision Res 35:1741-1754. CrossRef Medline

Krauzlis RJ, Liston D, Carello CD (2004) Target selection and the superior colliculus: goals, choices and hypotheses. Vision Res 44:1445-1451. CrossRef Medline

McLean RA, Sanders WL, Stroup WW (1991) A unified approach to mixed linear models. Am Stat 45:54-64.

Mohney BG (2007) Common forms of childhood strabismus in an incidence cohort. Am J Ophthalmol 144:465-467. CrossRef Medline

Noudoost B, Chang MH, Steinmetz NA, Moore T (2010) Top-down control of visual attention. Curr Opin Neurobiol 20:183-190. CrossRef Medline

Nusz KJ, Mohney BG, Diehl NN (2006) The course of intermittent exotro- pia in a population-based cohort. Ophthalmology 113:1154-1158. CrossRef Medline

Packer O, Diller LC, Verweij J, Lee BB, Pokorny J, Williams DR, Dacey DM, Brainard DH (2001) Characterization and use of a digital light projector for vision research. Vision Res 41:427-439. CrossRef Medline

Robinson DA (1964) The mechanics of human saccadic eye movement. J Physiol 174:245-264. Medline

Romanchuk KG, Dotchin SA, Zurevinsky J (2006) The natural history of surgically untreated intermittent exotropia-looking into the distant future. J AAPOS 10:225-231. CrossRef Medline

Schall JD, Purcell BA, Heitz RP, Logan GD, Palmeri TJ (2011) Neural mechanisms of saccade target selection: gated accumulator model of the visualmotor cascade. Eur J Neurosci 33:1991-2002. CrossRef Medline

Schiller PH (1984) The superior colliculus and visual function. In: The handbook of physiology, Volume III, Chapter 11, pp 457-505.

Serrano-Pedraza I, Manjunath V, Osunkunle O, Clarke MP, Read JC (2011) Visual suppression in intermittent exotropia during binocular alignment. Invest Ophthalmol Vis Sci 52:2352-2364. CrossRef Medline

Tatler BW, Hayhoe MM, Land MF, Ballard DH (2011) Eye guidance in natural vision: reinterpreting salience. J Vis 11(5):5. CrossRef Medline

Tychsen L, Burkhalter A (1997) Nasotemporal asymmetries in V1: ocular dominance columns of infant, adult, and strabismic macaque monkeys. J Comp Neurol 388:32-46. CrossRef Medline

van Leeuwen AF, Collewijn H, de Faber JT, van der Steen J (2001) Saccadic binocular coordination in alternating exotropia. Vision Res 41:34253435. CrossRef Medline

Walton MM, Ono S, Mustari M (2014) Vertical and oblique saccade disconjugacy in strabismus. Invest Ophthalmol Vis Sci 55:275-290. CrossRef Medline

Wang X, Zhang M, Cohen IS, Goldberg ME (2007) The proprioceptive representation of eye position in monkey primary somatosensory cortex. Nat Neurosci 10:640-646. CrossRef Medline

Weber RB, Daroff RB (1971) The metrics of horizontal saccadic eye movements in normal humans. Vision Res 11:921-928. CrossRef Medline

Wong AM, Lueder GT, Burkhalter A, Tychsen L (2000) Anomalous retinal correspondence: neuroanatomic mechanism in strabismic monkeys and clinical findings in strabismic children. J AAPOS 4:168-174. CrossRef Medline 